\title{
PARTITIONING AMONG NICHE AND NEUTRAL EXPLANATIONS FOR METACOMMUNITY PATTERNS IN CERRADO STREAM FISH COMMUNITIES
}

Thiago Bernardi Vieira ${ }^{1}$, Liriann Chrisley Nascimento da Silva ${ }^{*}$, Lilian Casatti ${ }^{2}$, Renato Romero ${ }^{2}$, Francisco Leonardo Tejerina Garro ${ }^{3}$, Pedro De Podestà Uchôa de Aquino $^{4}$, Paulo dos Santos Pompeu ${ }^{5} \&$ Paulo De Marco $\mathrm{Jr}^{6}$.

${ }^{1}$ Programa de Pós Graduação em Biodiversidade e Conservação, Universidade Federal do Pará. Faculdade de Ciências Biológicas, Campus Altamira. Rua Coronel José Porfírio 2515, São Sebastião, CEP 68372-040, Altamira - PA Brasil.

2 UNESP, Universidade Estadual Paulista, Rua Cristóvão Colombo, 2265, 15054-470, São José do Rio Preto, SP, Brazil

3 Centro de Biologia Aquática, Pontifícia Universidade Católica de Goiás, Goiânia, Brasil and PPSTMA, UniEvangélica, Anápolis, Goiás, Brasil. garro@pucgoias.edu.br

${ }^{4}$ Departamento de Zoologia, Universidade de Brasília, Brasília, DF, Brazil Universidade Federal de Lavras-UFLA, CEP 37200-000, Lavras, Minas Gerais, Brazil;

${ }^{5}$ Programa de Pós-graduação em Ecologia Aplicada, Departamento de Biologia,

${ }^{6}$ Theory, Metapopulation and Landscape Lab, Departamento de Ecologia, Instituto de Ciências Biológicas, Universidade Federal de Goiás Campus II, Caixa Postal 131, Goiânia, GO CEP 74001-970, Brazil.

*corresponding author: lirianncns@gmail.com 


\section{Abstract}

The Species Sorting concept, one of the models developed to explain patterns in

24 metacommunity structure, suggests that relationships between biological communities

25 and environmental conditions is the basic means of the species selection processes. A

26 second concept is neutral theory, and the idea of neutral dynamics underpinning

27 metacommunity structure, cannot be overlooked. The third mechanism is the Mass

28 Effect concept, that focuses on the interaction between environmental condition and neutral effects. In the present study, we partitioned fish communities in streams between niche and neutral theory concepts, identifying the best representation of metacommunity structure, and assessed if linear and hydrographic distance were equivalent in the representation of neutral processes. The result points to the importance of species sorting mechanisms in structuring fish communities with neutral processes best represented by the linear distances. On the other hand, the best representation of species' niches was achieved with average values and variance of the local conditions.

37 Key words: Ichthyofauna, Connectivity, stream network, Mass Effect, Specie Sorting, Environmental gradient. 


\section{Introduction}

Fish stream communities favors the explicitly evaluation of current metacommuity theories. On one side, a classical interpretation of the relationships between environmental conditions and the composition of fish communities is closely linked to Niche theory, predicting that the resources and conditions of a given environment dictate the distribution of species over space and time [1]. Studies of relationships between species composition, environmental conditions (e.g. water temperature, dissolved oxygen content, substrate type) and resources (e.g. places of refuge, food) have had an important impact on our understanding of how those systems work [1]. Considering the four general models currently used to explain metacommunity patterns [2], Species-Sorting assumes that the environment gradient is the only factor structuring the communities [3-7]. On the other hand, the explicitly spatial strucuture of riverine systems [8] and the existence of some complex models of linkage among aquatic habitats within basin (e.g. river pulse and marginal lakes), favors the view that dispersal within the metacommunity may account for a signification portion of the explanation of species composition patterns [7]. This later explanation is usually refered as a neutral framework [2]. Even though both factors may interact, we are still looking for a set of more general predictions from which it is expected that each of the models can be better applied.

The effect of environmental conditions such as water velocity, dissolved oxygen and water temperature successifully explain common patterns observed on fish communities of tropical streams [9-14]. Nevertheless, the choice of environmental descriptors and the quality of its statistical description is subject to doubts. Often these conditions are measured as a single value $[12,15]$. In contrast, the use of repeated 
measurements [e.g.: 11,16-18] may favor a better description of the natural stochasticity of environmental conditions in streams. Better designs for environmental conditions measurement may account for environmental heterogeneity of the stream system, which is recognized a long time [19-21], but frequently neglected. Environmental heterogeneity can have important effects on biological diversity [22,23], suggesting that variation of in-stream conditions is a more important predictor of fish species diversity [e.g.: 19-21], and others aquatics communities than average values [e.g.: 24,25]. For example, the relationship between aquatic macroinvertebrate diversity and the heterogeneity of substrates in streams [26-28].

Dispersal-related process may also exert some challenges related to data acquisition and interpretation The Neutral Theory [29] proposes that all individuals of the same trophic guild, have the same ability to compete (regardless of resources and present conditions at the place), thus having constant growth in any environment. In such scenario the author proposes that dispersal is the main source of increase local community diversity at an ecological time framework. Thus, it is expected that the spatial component (distance between sampling sites) or geographical barriers (physical obstacles to migration between locations) are the only mechanisms responsible for structuring the community. In the studies of stream ecology, we observe the frequent use of linear distance as a measurement of connectivity. However this distance may be not informative, since strict aquatic organisms (such as fish) can only move through the hydrographic network. Connectivity measures based on the stream network is beginning to be used in the interpretation of patterns on estuarine fish communities [e.g.: 30] and other aquatic organisms [e.g.: 28,31,32]. The main problem of the use of linear distances is the comparison of streams present in different hydrographic units. Usually, 
streams in the same basin (or sub-basins) are more similar than streams in different basins even if streams in different basins are geographically closer (linear distance) than streams within the same basin (hydrographic distance) [28].

There is no simple dichotomy between communities structured by Niche processes and neutral processes in nature [3], as many natural communities are structured both by local conditions and resources (Niche-related processes), and species' dispersion abilities [3,33]. The combined effects of different processes on communities are united under the theory of Mass-effects [2], which describes metacommunity processes as the product of both environmental gradients and the dispersal ability of the species. The quantification of the relative importance of niche and neutral processes can be evaluated using variance partitioning techniques [3,20,34]. These techniques allow to quantifying the percentage explanation related only to environmental conditions and resources, only to space, and to the interaction between the two sets [35]. Obviouly, the choice of descriptive variables for both sets environment and space - may have a determinant effect on the results and on the interpretation of how both explanations interact.

The evaluation of how space and environmental variables are related to community composition allow to a more explicity analysis of the now classic mechanisms for metacommunity patters developed by Leibold et al [2]. Communities that relate solely to the environmental gradient would be structured by the Species sorting mechanism, whereas communities that relate only to space are structured by Neutral or Patch Dynamics, and the interaction between space and the environmental gradient is taken as communities where Mass-Effect processes are predominant $[2,3]$. In the present study, our goals were: (i) identify the best representation of local conditions 
112 (average values or variance of conditions), and (ii) evaluate the importance of linear and

113 hydrographic distance in Neutral processes; (iii) evaluate the relative explanatory power

114 of environmental and space variables in order to determine wich of the four models

115 proposed by Leibold account for observed patterns in Brazilian Cerrado fish

116 communities.

117 Materials and Methods

To test the hypotheses we used a database composed of 76 streams of three

distinct hydrographic regions of Brazil: i) Araguaia-Tocantins; Ii) Paraná; and iii) São

Francisco, with all streams are located in the Cerrado biome (Figure 1). All sampled

streams are first- to third-order, georeferenced and the ichthyofauna was sampled by

trawl or electric fishing at least $50 \mathrm{~m}$ from the channel. The local conditions measured were turbidity, conductivity, $\mathrm{pH}$, dissolved oxygen, velocity, width and depth in at least three points of each stream.

Figure 01 - Location of the 76 streams (points) used in the work in three hydrographic regions in the Brazilian Cerrado.

As the points sampled are geographically aggregated, the autocorrelation of the data was tested through the Moran's Index. Spatial maps of suitable vectors are considered the best way to control autocorrelation and are good representatives of the spatial structure present in the data [36]. The eigenvectors of the first eigenvalues are related to the local structuring of communities, species with small dispersion skills. In order to perform spatial eigenvectors maps is necessary to know the relationship between all pairs of points present in the analysis, known as the Weight (W) Matrix 
linear distance between all streams (Appendix 2); ii) Local W (Appendix 1 - S1 - LW), defined by the linear distance between streams present in the same hydrographic unit.

Streams in different units had no interaction and connectivity values equal to zero distance. The same way as in Local W, streams in different units had no interaction and connectivity values equal to zero (Appendix 2); and iv) W Hydalt (Appendix 1 - S1 HW), defined by the hydrographic distance between the points weighted by the slope (Appendix 2).

We measured ecological diversity using two distinct metrics: (i) species richness and

(ii) beta diversity. Species richness was defined as the number of species present at the site of interest. The beta diversity was calculated according to the procedure described by Baselga [38], which defines beta diversity as the Sorensen dissimilarity index.

Diversity indices were calculated for both the total fish community and for different feeding guilds (i.e. detritivores, insectivores and omnivores).We used generalized linear models (GLM) to identify the best way to represent environmental conditions for streams fish communities. We compared models of community diversity indices and the average of the environmental conditions with a second model including the average together with the standard deviations of environmental conditions as predictor variables. This procedure was adopted to identify the best way to describe environment conditions, the average or variance. The GLM models was performed using all W matrices (Table 1) to identify the best means to represent neutral processes (linear or hydrographic distances). To avoid multicollinearity, a Principal Component Analysis

157 (PCA) was performed with the average values, and a second PCA with the average 
159 of explanation of the PCA being used as predictor variables on the models. After

160 identifying the best way to represent environmental conditions (mean or mean with

161 standard deviation), GLMs were performed for each trophic guild and all W matrices.

162 This procedure was used to identify if results found for the whole community were

163 equivalent to those found for individual feeding guilds.

164 Table 1 - Models used to determine the best set of descriptors of environmental

165 conditions and spatial structure, considering the richness and beta diversity of

166 ichthyofauna.

\begin{tabular}{cll}
\hline Diversity Metric & W Matrix & Environmental Condition \\
\hline & Global W & $\begin{array}{l}\text { Average } \\
\text { Average plus Standard Deviation }\end{array}$ \\
\cline { 2 - 3 } Richness & Local W & $\begin{array}{l}\text { Average } \\
\text { Average plus Standard Deviation }\end{array}$ \\
\cline { 2 - 3 } & Water W & $\begin{array}{l}\text { Average } \\
\text { Average plus Standard Deviation }\end{array}$ \\
\cline { 2 - 3 } Beta Diversity & Global W & $\begin{array}{l}\text { Average } \\
\text { Average plus Standard Deviation }\end{array}$ \\
\cline { 2 - 3 } & Local W & $\begin{array}{l}\text { Average } \\
\text { Average plus Standard Deviation }\end{array}$ \\
\cline { 2 - 3 } & Water W & $\begin{array}{l}\text { Average } \\
\text { Average plus Standard Deviation }\end{array}$ \\
\cline { 2 - 3 } & Hydalt W & $\begin{array}{l}\text { Average } \\
\text { Average plus Standard Deviation } \\
\text { Average plus Standard Deviation }\end{array}$ \\
\hline
\end{tabular}

167 All analyses were performed in the Spatial Analysis for Macroecology - SAM [39]. For

168 all models, we compute the Moran's I and the Akaike Information Criterion (AIC) and

169 the Variation of the AIC ( $\triangle \mathrm{AIC})$. To test relative effects of different metacommunity

170 processes, variance was partitioned into: i) environmental conditions; ii) spatial

171 processes; iii) shared variance between the environmental and space; and iv) not

172 explained.

173 Results 
with values of Moran's I higher than 0.1 (Table 2). Richness of omnivores showed the greatest degree of spatial structure (Moran's $I=0.316, p<0.001$ ), and the richness of detritivores the lowest (Moran's $\mathrm{I}=0.120, \mathrm{P}=0.010$ ). The beta diversity of the detritivores, insectivores and omnivores presented non-significant effects of spatial autocorrelation.

Table 2 - Autocorrelation index of Moran (Moran's I) performed for richness and beta I/I(max) - The Moran's I corrected by maximum value.

\begin{tabular}{llcrcc}
\hline Diversity Metric & Ichthyofauna & Moran's I & \multicolumn{1}{c}{$\mathrm{p}$} & $\mathrm{I}(\max )$ & $\mathrm{I} / \mathrm{I}(\mathrm{max})$ \\
\hline \multirow{4}{*}{ Richness } & All & 0.234 & $<0.001$ & 0.737 & 0.318 \\
& Detritivorous & 0.120 & 0.010 & 0.610 & 0.198 \\
& Insectivorous & 0.180 & $<0.001$ & 0.628 & 0.287 \\
& Omnivorous & 0.316 & $<0.001$ & 0.807 & 0.392 \\
\hline \multirow{4}{*}{ Beta Diversity } & All & 0.208 & $<0.001$ & 0.758 & 0.274 \\
& Detritivorous & 0.052 & 0.211 & 0.680 & 0.076 \\
& Insectivorous & 0.020 & 0.517 & 0.551 & 0.037 \\
& Omnivorous & -0.039 & 0.618 & 0.748 & -0.052 \\
\hline
\end{tabular}

The PCA performed with average values of the environmental conditions explained $33.26 \%$ of variation in fish diversity in the first axis, and $18.79 \%$ in the second axis, and a total of 52.05\% across both axes (Appendix 3). The pattern found by the ranking was: (i) Conductivity, Ph, Dissolved Oxygen and Channel Width positively related to the first axis; (ii) Turbidity and Current Speed positively to the second axis; and (iii), Channel Depth negatively to the second axis (Appendix 3). The PCA 190 performed with both average values and standard deviation of environmental conditions 191 explained $21.02 \%$ of variance in the first axis and $16.66 \%$ in the second axis (Appendix 3). The pattern found by the ranking was: (i) Standard deviation of the channel width, 
193 Standard deviation and Average Turbidity and Current Speed positively related to the

194 first axis; (ii) Standard Deviation and Average Depth of the channel and the Standard

195 Deviation of $\mathrm{Ph}$, Conductivity and Oxygen dissolved negatively to the first axis; and

196 (iii) Average Channel Width, Ph, Dissolved Oxygen and Conductivity and the Standard

197 Deviation of Water Temperature positively to the second axis (Appendix 3).

Best models of richness and beta diversity of fish species from included average and standard deviation of the local conditions and the spatial eigenvalues maps performed from Local W (Appendix 3). The richness model had a high r-squared value $\left(\mathrm{r}^{2}=0.623\right)$, with $56.30 \%$ of variance explained by environmental conditions, $6 \%$ by spatial maps and $0.3 \%$ by interactions between niche and neutral effects (Appendix 3). Beta diversity had an even higher $r$-square value $\left(r^{2}=0.758\right)$, with $64.40 \%$ of variance explained by environmental conditions, $6.70 \%$ by spatial maps, and $4.80 \%$ by interactions between environmental and spatial processes (Appendix 3).

When the community was partitioned into trophic guilds, richness and beta diversity of insectivorous and omnivorous species presented the spatial eigenvalues maps, performed from the $\mathrm{W}$ Local matrix, as the best representation of spatial processes (Appendix 3). However, for detritivores, the W Hydalt model was the best representation of spatial processes (Appendix 3).

\section{Discussion}

In the analyses of richness and beta diversity, we found environmental conditions captured most of the variation in fish species diversity, suggesting that environmental conditions were satisfactorily represented using average values, and the 
216 processes and association with dispersion, made using spatial eigenvalue maps, has to

217 be done carefully. Spatial eigenvalue maps bring not only information on spatial

218 structuring but also environmental conditions [40,41].

As for beta diversity in different guilds, especially insectivores and the omnivores, showed little relation with environment conditions and a greater correlation with spatial processes. This result may be explain by the spatial component representing collinear unmeasured environmental conditions rather than effects of space itself, or that insectivorous and omnivorous fish have greater dispersion abilities. A higher dispersal capacity can hide effects of environmental gradients, as species can rapidly colonize sites that have unfavorable conditions, and suppress effects of local extinction [42]. If this was the case for insectivorous and omnivorous species, Mass Effects may be the predominant mechanism structuring their communities. In contrast, detritivores and the total community were structured by Species Sorting effects, or an interaction between Mass Effects and Species Sorting [3], as these communities showed a strong relationship with environmental conditions and little correlation with space.

Although the Local W model was the best representation of space for the entire ichthyofauna community, we observed a weak relationship between fish communities (richness and total beta diversity) and spatial components. This weak association may have occurred due two factors: (i) The ability of fish to actively select habitats would be more important than dispersion, indicating the Species-Sorting mechanism of metacommunity structure [2]. Species Sorting is considered the main mechanism

237 responsible for structuring natural meta communities $[3,4,6,7]$. On the other hand, (ii) 238 the "path" along which fish species have dispersed is environmentally unsuitable, restricting their dispersion [42]. Although the characteristics of streams were controlled 
in order to be representative of natural conditions, the connection between these points was not controlled. Thus, it may be that sites, although preserved, are connected by nonprocess in stream fishes communities. The use of the linear distance is a simplistic and insufficient means measuring spatial processes in aquatic systems [7]. When including the geographic barriers into the linear distance procedure (called Local W here), the linear distance was able to provide a good representation of the geographic patterns of this fish community. The performance of Local $\mathrm{W}$ is better than the dendritic distance (W Water), shown previously as the best means to represent spatial processes in aquatic systems. Using Local $\mathrm{W}$, we were able to identify a simple and robust way of representing spatial processes considering the physical barriers separating communities. This result was consistent across all components of the community (i.e. overall community or discrete feeding guilds) and ecological descriptors (i.e. species richness or beta diversity.

A second feature of our results is related to the dispersion of detritivorous fish, which cannot be represented using simple euclidian distances between points, considering or not considering geographic barriers, or hydrological distances. The best way to represent space process in this guild was with the application of Hydalt W. These models consider the dendritic distance between points (and barriers), and the direction of the flow. The application of connectivity models associated with flow

261 direction is advocated by some authors as being the most suitable for aquatic organisms

$262[43,44]$. However, with the analysis of our data, we observed that this approach, is more 
complex than the euclidian distance (considering barriers - Local W), and was only necessary for detritivorous fish.

The low dispersion present in the ichthyofauna of streams is evidenced in the eigenvalues are related to local structuring and higher eigenvalues to larger scale structuring $[37,45]$, we interpret that fishes from stream are dispersing across small scales, as richness and beta diversity were negatively related to the filters. This result supports the idea of preserved spots connected by altered "paths". Thus, species with low dispersal ability tend to express spatial structure more clearly than species with higher dispersal ability $[33,46]$. environmental gradients [2]. The interaction of space (dispersion) and environment in the structuring of metacommunities is attributed solely to the Mass Effects model [2]. However is it not possible to separate these two mechanisms, and metacommunities that are related to space and environment are understood as interaction between SpeciesSorting and Mass Effects [3,47-49]. This interaction was found in 29\% (46) of the communities analyzed by Cottenie [3] and also found for Amazonian fish [7,47-49].

280 However the ichthyofauna show a greater correlation with environmental conditions than spatial processes, suggesting that Species Sorting is the key mechanism in structuring fish communities (37\% of the metacommunity analyzed by Cottenie [3] show this result). This result does not rule out the occurrence of dispersion [3,7,47-49],

284 but reinforces the idea that dispersion occurs locally and weakly (negative relation with 285 the spatial eigenvectors maps). 
variation according to an environmental gradient [52]. Dispersion has little influence on metacommunity patterns at large scales $[42,50]$. In fact, dispersion decrease at large scales as the same way that environmental gradient increase the correlation with metacommunity structure $[42,46]$. In addition, fish can only migrate using drainage and some species tend not to migrate or are prevented from migrating due to physical barriers such waterfalls or dams. Furthermore, species that actively disperse tend to select the environment in which they will settle, further reducing effects of spatial structure [42].

The variation partitioning of fish communities between environmental conditions and geographic space tend to associate these sets of variables with niche (i.e. environmental conditions) or neutral (i.e. geographic distances) theory [53]. When communities are more correlated with environmental conditions than geographic distance, the communities are structured by niche theory. On the other hand, when the geographic distance are more correlated than environment, the discussion is focused on neutral theory. This dichotomous view is overly simplistic and does not reflect complexities of the multiple mechanisms that concurrently structure natural communities. Communities are not the effect of only one of these two theories, but the 307 interaction between them [54]. More recent analyses [3,4,42,46-49,55] demonstrate the association of the community with the mechanisms proposed by Leiboldet et al [2]. In this case, the relationship between communities and environmental conditions are 
310 related to the Species Sorting mechanism, the relationship between community and space to the neutral or Patch Dynamic mechanisms, and the interaction between space and conditions related to the Mass Effect mechanism [3]. However, the dissociation of Mass Effects and Species Sorting is not trivial, since the dispersion limitation in communities within Species-Sorting can produce a pattern with relationship between space and environmental conditions, a Mass Effect dynamic [3].

So we conclude that the ichthyofauna of Cerrado streams are structured by an interaction between Mass Effects and Species Sorting mechanisms. Only the beta diversity insectivores and omnivores differed, with stronger effects of space, suggesting an influence of neutral or Pach Dynamic models. Finally, we found that the linear distance measures that take into account the physical barriers (i.e. Local W) are the best representations of spatial patterns in fish communities. Although, analyses of detritivores required the addition of flow direction in connectivity models (Hydalt W). Regarding the environmental conditions, it is necessary that these are represented by average and some metric that measures their variation to best evaluate the degree of environmental heterogeneity.

\section{Acknowledgements}

We would like to thank the lab staff at the Aquatic Ecology Laboratory of the

UFC. TBV would like to thank Coordenação de Aperfeiçoamento de Pessoal de Nível Superior (CAPES) for the grant provided during his doctoral degree. Part of these study

was funded by CNPq/PPBIO (agreement \# 457463/2012-0) and CNPq/ICMBio

332 Fund for Ecological Research, grant no. 00543 and Aperfeiçoamento de Pessoal de 333 Nível Superior - Brasil (CAPES) Finance Code 001 
335 1. Hutchinson GE. Concludig remarks. Cold Spring Harb Symp Quant Biol. 1957;22: 415-427.

2. Leibold MA, Holyoak M, Mouquet N, Amarasekare P, Chase JM, Hoopes MF, et al. The metacommunity concept: a framework for multi-scale community ecology. Ecol Lett. 2004;7: 601-613. doi:10.1111/j.1461-0248.2004.00608.x

3. Cottenie K. Integrating environmental and spatial processes in ecological community dynamics. Ecol Lett. 2005;8: 1175-82. doi:10.1111/j.1461-

4. Van der Gucht K, Cottenie K, Muylaert K, Vloemans N, Cousin S, Declerck S, et al. The power of species sorting: local factors drive bacterial community 0248.2005.00820.x

5. Vanschoenwinkel B, Waterkeyn A, Jocqué M, Boven L, Seaman M, Brendonck composition over a wide range of spatial scales. Proc Natl Acad Sci U S A. 2007;104: 20404-20409. doi:10.1073/pnas.0707200104

6. Vanschoenwinkel B, De Vries C, Seaman M, Brendonck L. The role of metacommunity processes in shaping invertebrate rock pool communities along a dispersal gradient. Oikos. 2007;116: 1255-1266. Available: isi:000248681100001 
Spatial eigenfunction analyses in stream networks: do watercourse and overland distances produce different results? Freshw Biol. 2011;56: 1184-1192. doi:10.1111/j.1365-2427.2010.02563.x

8. Presley SJ, Higgins CL, Willig MR. A comprehensive framework for the evaluation of metacommunity structure. Oikos. 2010;119: 908-917. doi:10.1111/j.1600-0706.2010.18544.x

9. Penczak A, Agostinho AA, Okada EK. Fish diversity and community structure in two small tributaries of the Parana River, Parana State, Brazil. Hydrobiolo. 1994;294: 243-251.

10. Benedito-Cecilio E, Minte-Vera C V, Zawadzki CH, Pavanelli CS, Rodrigues FHG, Gimenes MF. Ichthyofauna from the Emas National Park region: composition and structure. Braz J Biol. 2004;64: 371-382. Available: http://www.ncbi.nlm.nih.gov/pubmed/15622836

11. Ferreira CDP, Casatti L. Influência da estrutura do hábitat sobre a ictiofauna de um riacho em uma micro-bacia de pastagem, São Paulo, Brasil. Rev Bras Biol. 2006;23: 642-651.

12. Aquino PPU, Schneider M, Silva MJM, Fonseca CP, Arakawa HB, Cavalcanti DR. Ictiofauna dos córregos do Parque Nacional de Brasília, bacia do Alto Rio Paraná, Distrito Federal, Brasil Central Ictiofauna dos córregos do Parque Nacional de Brasília, bacia do Alto Rio Paraná , Distrito Federal, Brasil Central. Biota Neotrop. 2009;9: 217-230.

13. Dias AM, Tejerina-Garro FL. Changes in the structure of fish assemblages in 
streams along an undisturbed-impacted gradient, upper Paraná River basin ,

14. Zeni JO, Casatti L. The influence of habitat homogenization on the trophic structure of fish fauna in tropical streams. Hydrobiologia. 2013;726: 259-270. doi:10.1007/s10750-013-1772-6

15. Esguícero ALH, Arcifa MS. The fish fauna of the Jacaré-Guaçu River basin , Upper Paraná River basin The fish fauna of the Jacaré-Guaçu River basin , Upper Paraná River basin. Biota Neotrop. 2011;11: 103-114.

16. Araújo NB, Tejerina-garro FL. Composição e diversidade da ictiofauna em riachos do Cerrado, bacia do ribeirão Ouvidor, alto rio Paraná, Goiás, Brasil Nicelly. Rev Bras Biol. 2007;24: 981-990.

17. Melo TL De, Tejerina-garro FL, Melo CE De. Influence of environmental parameters on fish assemblage of a Neotropical river with a flood pulse regime , Central Brazil. Neotrop Ichthyol. 2009;7: 421-428.

19. Angermeier PL, Schlosser IJ. Species-Area Relationship for Stream Fishes. Ecology. 1989;70: 1450-1462. doi:10.2307/1938204

20. Beisner BE, Peres-Neto PR, Lindström ES, Barnett A, Longhi ML. The role of environmental and spatial processes in structuring lake communities from 
21. Das MK, Naskar M, Mondal ML, Srivastava PK, Dey S, Rej A. Influence of ecological factors on the patterns of fish species richness in tropical Indian rivers. Acta Ichthyol Piscat. 2012. doi:10.3750/AIP2011.42.1.06

22. Vandermeer JH. Niche Theory. Annu Rev Ecol Syst. 1972;3: 107-132.

405

406

23. Whitaker Jr. JO. Food habits of bats from Indiana. Can J Zool. 1972;50: 877883. doi:10.1139/z72-118

24. Fukaya K, Okuda T, Nakaoka M, Noda T. Effects of spatial structure of population size on the population dynamics of barnacles across their elevational range. J Anim Ecol. 2014; 1334-1343. doi:10.1111/1365-2656.12234

25. Vieira TB, Dias-Silva K, Pacífico E dos S. Effects of riparian vegetation integrity on fish and Heteroptera communities. Appl Ecol Environ Res. 2013;13: 53-65. doi:10.15666/aeer/1301

26. Bond NR, Downes BJ. Flow-related disturbance in streams: An experimental test of the role of rock movement in reducing macroinvertebrate population densities. Mar Freshw Res. 2000;51: 333-337.

27. Olsen D a., Townsend CR, Matthaei CD. Influence of reach geomorphology on hyporheic communities in a gravel-bed stream. New Zeal J Mar Freshw Res. 2001;35: 181-190. doi:10.1080/00288330.2001.9516988

28. Landeiro VL, Bini LM, Melo AS, Pes AMO, Magnusson WE. The roles of dispersal limitation and environmental conditions in controlling caddisfly 
(Trichoptera) assemblages. Freshw Biol. 2012;57: 1554-1564. doi:10.1111/j.1365-2427.2012.02816.x

29. Hubbell SP. The Unified Neutral Theory of Biodiversity and Biogeography. Monogr Popul Biol. 2001;32: 375. doi:10.1111/j.1939-7445.2005.tb00163.x

30. Fullerton a. H, Burnett KM, Steel E a., Flitcroft RL, Pess GR, Feist BE, et al. Hydrological connectivity for riverine fish: measurement challenges and research opportunities. Freshw Biol. 2010; no-no. doi:10.1111/j.1365-2427.2010.02448.x

31. Obolewski K, Glińska-Lewczuk K, Kobus S. Effect of hydrological connectivity on the molluscan community structure in oxbow lakes of the Łyna River. Oceanol Hydrobiol Stud. 2009;38. doi:10.2478/v10009-009-0045-1

32. Jacobson R, Faust T. Hydrologic connectivity of floodplains, northern Missouri implications for management and restoration of floodplain forest communities in disturbed landscapes. River Res Appl. 2014;286: 269-286. doi:10.1002/rra

33. Thompson R, Townsend C. A truce with neutral theory: local deterministic factors, species traits and dispersal limitation together determine patterns of diversity in stream invertebrates. J Anim Ecol. 2006;75: 476-484. doi:10.1111/j.1365-2656.2006.01068.x

34. Peres-Neto PR, Legendre P. Estimating and controlling for spatial structure in the study of ecological communities. Glob Ecol Biogeogr. 2010;19: 174-184. doi:10.1111/j.1466-8238.2009.00506.x

35. Legendre P, Legendre L. Numerical ecology. Second english edition. Numerical Ecology Second English Edition. 2003. 
36. BINI LM, Diniz-Filho JAF, Rangel TFLVBLVBTFLV, Akre TSBB, Albaladejo RG, Albuquerque FS, et al. Coefficient shifts in geographical ecology: an empirical evaluation of spatial and non-spatial regression. Ecography (Cop). 2009;32: 193-204. doi:10.1111/j.1600-0587.2009.05717.x

37. Grffith DA, Peres-Neto PR, Griffith D a., Peres-Neto PR. Spatial Modeling in Ecology: The Flexibility of Eigenfunction Spatial Analyses. Ecology. 2006;87: 2603-2613. doi:10.1890/0012-9658(2006)87[2603:SMIETF]2.0.CO;2

38. Baselga A. Multiplicative partition of true diversity yields independent alpha and beta components; additive partition does not. Ecology. 2010;91: 1974-81. Available: http://www.ncbi.nlm.nih.gov/pubmed/20715618

39. Rangel TFLVB. Study Guide to Practical Classes in SAM. Structure. 2010; 1-76.

40. Diniz-Filho JAF, Bini LM, Hawkins BA. Spatial autocorrelation and red herrings in geographical ecology. Glob Ecol Biogeogr. 2003. doi:10.1046/j.1466822X.2003.00322.X

41. Hawkins B a, Albuquerque FaS, Araújo MB, Beck J, Bini LM, Cabrero-Sanudo, Francisco J, et al. Concepts \& Synthesis a Global Evaluation of Metabolic Theory As an Explanation. Ecology. 2007;88: 1877-1888. doi:10.1890/061444.1

42. Grönroos M, Heino J, Siqueira T, Landeiro VL, Kotanen J, Bini LM. Metacommunity structuring in stream networks: roles of dispersal mode, distance type, and regional environmental context. Ecol Evol. 2013;3: 4473-87. doi:10.1002/ece3.834 
465

466

467

468

43. Pearson RG, Raxworthy CJ, Nakamura M, Townsend Peterson A. Predicting species distributions from small numbers of occurrence records: A test case using cryptic geckos in Madagascar. J Biogeogr. 2007;34: 102-117. doi:10.1111/j.1365-2699.2006.01594.x

44. Peterson EE, Ver Hoef JM. A mixed-model moving-average approach to geostatistical modeling in stream networks. Ecology. 2010;91: 644-51. Available: http://www.ncbi.nlm.nih.gov/pubmed/20426324

45. Blanchet FG, Legendre P, Borcard D. Modelling directional spatial processes in ecological data. Ecol Modell. 2008;215: 325-336. doi:10.1016/j.ecolmodel.2008.04.001

46. Astorga A, Heino J, Luoto M, Muotka T. Freshwater biodiversity at regional extent: determinants of macroinvertebrate taxonomic richness in headwater streams. Ecography (Cop). 2011;34: 705-713. doi:10.1111/j.16000587.2010.06427.x

47. Vieira TB, Tejerina-Garro FL. Relationships Between Environmental Conditions And Fish Assemblages In Tropical Savanna Headwater Streams. Sci Rep. 2020;10: 2174. doi:10.1038/s41598-020-59207-9

48. Vieira TB, Brasil LS, Raiol Torres N, Lima de Melo T, Moreira EA, Bastos RP, et al. Fish in the matrix: effects of landscape on community-structure patterns of the ichthyofauna of streams in Cerrado. Mar Freshw Res. 2020. doi:10.1071/MF19281

49. Brasil LS, Silverio DV, Cabette HSR, Batista JD, Vieira TB, Dias-Silva K, et al. 
Net primary productivity and seasonality of temperature and precipitation are predictors of the species richness of the Damselflies in the Amazon. Basic Appl Ecol. 2019;35: 45-53. doi:10.1016/j.baae.2019.01.001

50. Heino J, Schmera D, Eros T. A macroecological perspective of trait patterns in stream communities. Freshw Biol. 2013;58: 1539-1555. doi:10.1111/fwb.12164

51. Hoverman JT, Davis CJ, Werner EE, Skelly DK, Relyea RA, Yurewicz KL. Environmental gradients and the structure of freshwater snail communities. Ecography (Cop). 2011;34: 1049-1058.

52. Heino J, Melo AS, Siqueira T, Soininen J, Valanko S, Bini LM. Metacommunity organisation, spatial extent and dispersal in aquatic systems: patterns, processes and prospects. Freshw Biol. 2014; 845-869. doi:10.1111/fwb.12533

53. Smith TW, Lundholm JT. Variation partitioning as a tool to distinguish between niche and neutral processes. Ecography (Cop). 2010;33: 648-655.

54. Juen L, de Marco P. Dragonfly endemism in the Brazilian Amazon: Competing hypotheses for biogeographical patterns. Biodivers Conserv. 2012;21: 35073521.

55. Heino J. A macroecological perspective of diversity patterns in the freshwater realm. Freshw Biol. 2011;56: 1703-1722. doi:10.1111/j.1365-2427.2011.02610.x 


\section{Supporting information captions}

508 Appendix 01 - Weight (W) Matrix used in the analysis. i) Global W (S1 - GW); ii)

509 Local W (S1 - LW); iii) Water W (S1 - WW); iv) W Hydalt (S1 - HW).

510 Appendix 02 - Procedures performed to calculate all W matrices

511 Appendix 03 - Results from PCA analyses and GLM procedures performed with

512 communities, environmental conditions and space processes. 


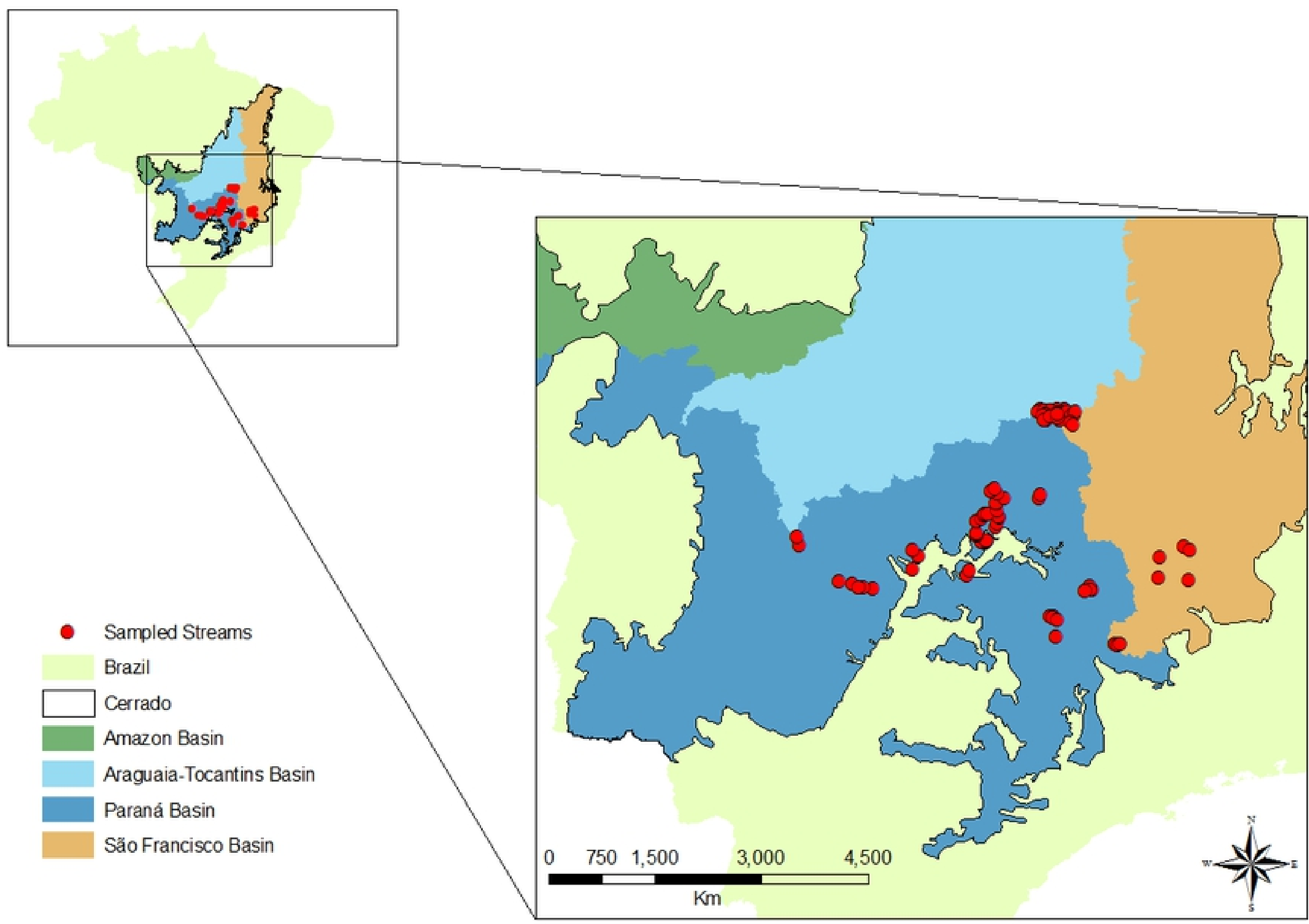

Figure 1 